\title{
BUSINESS MODEL INNOVATION FOR CIRCULAR ECONOMY: INTEGRATING LITERATURE AND PRACTICE INTO A PROCESS MODEL
}

\author{
M. P. P. Pieroni ${ }^{凶}$, T. C. McAloone and D. C. A. Pigosso \\ DTU-Technical University of Denmark, Denmark \\ $\triangle$ mdpp@dtu.dk
}

\begin{abstract}
To implement circular economy, manufacturers will need to develop new business models. Available approaches are granular, generic, infrequently focusing on advice or implementation, and lacking practical demonstration. This article presents how a tool was proposed to cover these gaps. Based on design research methodology, twenty-two conceptual and practical requirements were identified and translated in functions for the development of the Circular Economy Business Model Configurator, a tool that supports manufacturers in strengthening proposals of business models for circular economy.
\end{abstract}

Keywords: circular economy, business models, design tools, configurator

\section{Introduction}

Circular economy (CE) has been disseminated as an umbrella concept since the 2010's (Blomsma and Brennan, 2017) with the purpose of establishing a resource-effective and efficient economic system that is suitable to sustainable development (Geissdoerfer et al., 2017; Schroeder et al., 2019). To implement $\mathrm{CE}$, industrial and consumption systems will need to shift their foundations to build on renewable energy and materials sources and to reduce waste generation by intentionally narrowing, slowing and closing material and energy flows (Bocken et al., 2016; Böhringer and Rutherford, 2015).

For manufacturing companies, the adoption of $\mathrm{CE}$ as a business strategy implies in providing and maintaining products with the highest value while consuming as few resources as possible (McAloone, 2019). The main challenge is to reduce the so-called 'structural waste' (Böhringer and Rutherford, 2015) caused by design (e.g. fast obsolescence), sub-optimal processes, outdated laws, lack of motivation or unconcerned behaviour from receivers (e.g. overconsumption or misuse of products) (Böhringer and Rutherford, 2015; McAloone, 2019). To build organizational capabilities for CE, manufacturers will need to advance not only technological or product innovation, but also the systemic value innovation with the configuration of new business models (BM) which have fit with CE principles (Pieroni et al., 2019a; Schulte, 2013). Business models explain how businesses work by providing a "design or architecture of the value creation, delivery, and capture mechanisms" (Teece, 2010).

Business models for circular economy (i.e. especially the ones focused on reuse and remanufacturing, sharing of underutilized capacity, and the provision of services or functionalities rather than products) represent no more than $5 \%$ to $10 \%$ of revenues in many industrial sectors (OECD, 2018). This bottleneck in market penetration indicates a need for research to support scaling up and dissemination 
of CE-oriented BMs. Especially in the case of manufacturing companies, designing and implementing new business models is challenging (Lieder and Rashid, 2016; Pieroni et al., 2019c). Our hypothesis is that adequate knowledge created to and with businesses (Andreasen, 2011) could accelerate and prompt change by demonstrating viability, economic feasibility, and advantages of the business models for CE (Bocken et al., 2019; Kirchherr and van Santen, 2019; Lieder and Rashid, 2016).

Different approaches to support business model innovation for circular economy are already available. However, according to recent systematic literature reviews, the existing approaches present shortcomings. For example, their level of discussion is granular (i.e. lacking coverage of all stages from design to implementation), generic (i.e. lacking specifics or contextual sensitivity for sectors), and infrequently focusing on proactive advice and implementation. Additionally, they lack recommendations for decision-support practices and practical demonstration on how they could support translating conceptual knowledge into impactful actions for companies (Bocken et al., 2019; Garetti et al., 2012; Kirchherr and van Santen, 2019; Pieroni et al., 2019a; Rosa et al., 2019).

To advance scientific knowledge while diminishing the practical gap, the objective of this research is to specify the essential requirements and functions for the initial conceptualisation of a tool that can help manufacturing companies and their business developers, sustainability managers, or product managers with configuring business models for circular economy. The configuration includes identifying opportunities, designing, and assessing circular economy business models (CEBMs).

With a design research methodology (section 2), this paper explores requirements for a tool to support business model innovation for $\mathrm{CE}$ in literature and practice, which included action research cycles with seven manufacturers (section 3). Then, by translating the conceptual and practical requirements in functions, a new tool called Circular Economy Business Model Configurator is proposed to support the integration of CE principles in manufacturing companies' BM innovation process (section 4). Finally, a discussion is provided about future research steps and the concluding remarks are presented (section 5).

\section{Research methodology}

The adopted research framework based on design research methodology (Blessing and Chakrabarti, 2009) was organized in five stages. It included an initial research clarification and two cycles (I and II) of descriptive studies followed by prescriptive studies (Figure 1).

Research clarification comprised the identification of the research gap and the definition of the need for scientific investigation in the format of research questions:

- RQ1 - What are the requirements for a tool to support circular economy business model innovation within manufacturing companies?

- RQ2 - How to transfer the requirements into an effective and useful approach (i.e. format/means) for the real world practice?

Descriptive study I was based on a systematic review of academic and practitioners' contributions to literature (documented in Pieroni et al. (2019a)). This resulted in the identification and systematization of more than $90 \mathrm{CE} /$ sustainability business model innovation approaches (step 1). The approaches comprised both descriptive (i.e. conceptual frameworks describing characteristics of business models or business model innovation/design), and prescriptive works (i.e. process models and tools suggesting ways to design or innovate business models). Gaps that emerged from the comparison among approaches allowed the identification of initial conceptual requirements for the tool. These were complemented by recommendations from a similar systematic literature review about tools for CEBM innovation (Bocken et al., 2019) (step 2). Due to a lack of detailed studies about BM innovation in the industry (Bocken et al., 2019; Kirchherr and van Santen, 2019; Rosa et al., 2019), hypotheses were created based on the key conceptual requirements for their verification in practice (step 3).

Prescriptive study I aimed to prepare the experimental setting to test the hypotheses about the key conceptual requirements. For that, core characteristics/functions of the tool were specified based on the hypotheses and our personal view of the role of tools to support CEBM innovation/design (i.e. obtained after the experience with the action research cycles) (step 4). Then, a low-fidelity prototype (i.e. paper-based templates and non-interactive spreadsheets) was developed and refined by means of action research with seven manufacturing companies (documented in Pieroni et al., 2019c) (step 5). 
Descriptive study II aimed to evaluate the validity of the hypotheses and to obtain initial insights about the usefulness of the low-fidelity prototype of the tool. The evaluation was conducted by means of: i) structured questionnaires answered by the companies after the use of the low-fidelity prototype, and; ii) the researchers' observations collected during the action research cycles (documented in Pieroni et al., 2019b). Suggestions of improvements that emerged from the evaluation were catalogued according to a coding process by describing the scope of improvement, company and participant suggesting it (Yin, 2011) (step 6). The suggestions of improvements were analysed and converted into initial practical requirements based on three inclusion criteria: (1) aligned with the scope of the tool, (2) feasible, and (3) implementable by the researchers (step 7). The set of initial conceptual and practical requirements were categorized in: 'must-be' or attractive depending on the degree of importance for the characteristics according to literature and users (Matzler and Hinterhuber, 1998). Finally, they were translated into more specific requirements by indicating how to implement the initial requirements (Blessing and Chakrabarti, 2009) (step 8).

Prescriptive study II intended to answer the second research question. The final set of conceptual and practical requirements identified in previous stages was used for the specification of the main functions of the tool (step 9). This enabled the development of a high-fidelity prototype in the format of an interactive support tool hosted on a spreadsheets software program (step 10).

The results of each stage are presented in the following sections as indicated in Figure 1.

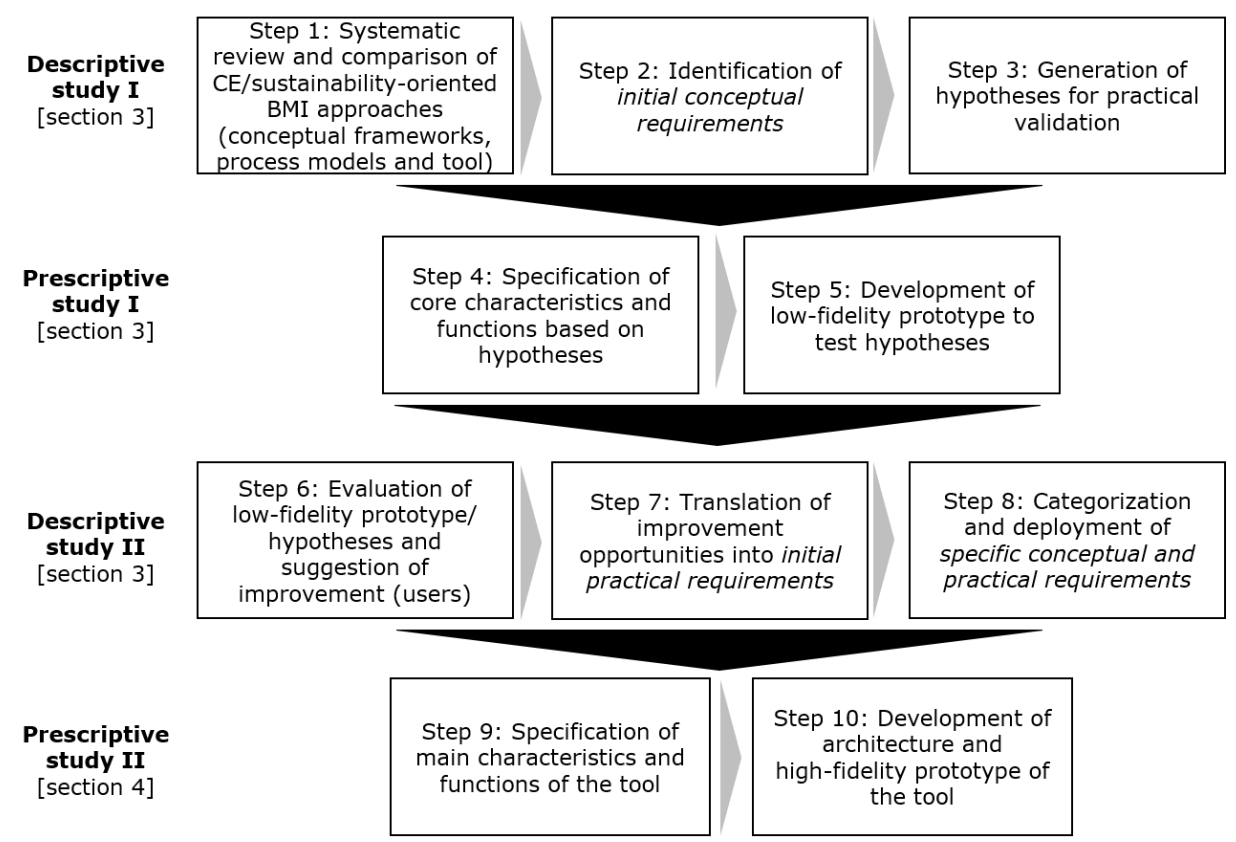

Figure 1. Research methodology

\section{Collecting requirements from theory and practice}

This section provides answers for RQ1. It introduces the concept of requirements and presents the requirements for the tool.

A requirement is defined as a "characteristic which a designer is expected to fulfil through the eventual design" (Chakrabarti et al., 2004, p. 22). Having a requirements plan is one of the first and fundamental steps for developing a product or software (Boehm, 1984; Chakrabarti et al., 2004). The same logic can be applied for developing methods or tools to support designers (Blessing and Chakrabarti, 2009). Different methods for collection of requirements might exist, ranging from checklists, QFD methods, or the combination of both as software support (Chakrabarti et al., 2004; Pacheco and Garcia, 2012).

Moreover, different categories and levels of requirements exist depending on how they can influence the stakeholders' perception (e.g. direct users; indirect users) and satisfaction about the product, software, methods, or tools (Matzler and Hinterhuber, 1998). 
In this research we differentiate three categories and two relevance levels of requirements to support the development of the intended tool (Matzler and Hinterhuber, 1998). The relevance levels are:

1. Must-be: key criteria that when not fulfilled will cause dissatisfaction and resistance from stake-holders. However, they will not impress the stakeholders if they exist (i.e. minimum requirements).

2. Attractive: criteria that when fulfilled lead to impression or over satisfaction in stakeholders. However, there is no dissatisfaction if they are not present (i.e. nice-to-have requirements).

The Circular Economy Business Model (CEBM) Configurator is a planning tool to support manufacturing companies in the early stage of developing new business models for circular economy. In total, 22 requirements were identified for this scope of tool. The literature review enabled the identification of 13 conceptual requirements (R1-R13) and 5 specific conceptual requirements (R7.1R7.2; R13.1-R13.3) (Table 1). These requirements cover different categories, including (i) the way the tool is developed (R1-R5); (ii) usability and application (R6-R9); and (iii) content (R10-R13).

Table 1. Conceptual requirements (R) (Legend: (i) the way the tool is developed; (ii) usability and application; and (iii) content)

\begin{tabular}{|c|c|c|c|c|}
\hline Code & Requirement description & Relevance & Category & References \\
\hline R1 & $\begin{array}{l}\text { The tool should be developed from literature \& } \\
\text { practice }\end{array}$ & Attractive & (i) & Bocken et al. (2019) \\
\hline R2 & $\begin{array}{l}\text { The tool should be iteratively developed and tested } \\
\text { with potential users }\end{array}$ & Attractive & (i) & Bocken et al. (2019) \\
\hline R3 & $\begin{array}{l}\text { The tool should be purpose-made for CE, e.g., } \\
\text { fulfilling CE learning needs and bringing knowledge } \\
\text { from different disciplines }\end{array}$ & Attractive & (i) & $\begin{array}{l}\text { Bocken et al. (2019); } \\
\text { Pieroni et al. (2019a) }\end{array}$ \\
\hline R4 & $\begin{array}{l}\text { The tool should be evaluated by practitioners in its } \\
\text { final version }\end{array}$ & Attractive & (i) & Bocken et al. (2019) \\
\hline R5 & $\begin{array}{l}\text { The tool should be simple and not too time- } \\
\text { consuming }\end{array}$ & Attractive & (ii) & Bocken et al. (2019) \\
\hline R6 & The tool should be adaptable to different contexts & Must be & (ii) & Bocken et al. (2019) \\
\hline R7 & The tool should be prescriptive & Must-be & (ii) & $\begin{array}{l}\text { Bocken et al. (2019); } \\
\text { Pieroni et al. (2019a) }\end{array}$ \\
\hline R7.1 & $\begin{array}{l}\text { The tool should provide a transparent procedure and } \\
\text { guidance on how others can use the tool }\end{array}$ & Must-be & (ii) & $\begin{array}{l}\text { Bocken et al. (2019); } \\
\text { Pieroni et al. (2019a) }\end{array}$ \\
\hline R7.2 & $\begin{array}{l}\text { The tool should enable low requirement of external } \\
\text { facilitation (i.e. knowledge embedded in the tool) }\end{array}$ & Attractive & (ii) & $\begin{array}{l}\text { Bocken et al. (2019); } \\
\text { Pieroni et al. (2019a) }\end{array}$ \\
\hline R8 & The tool should inspire or trigger business change & Must-be & (ii) & $\begin{array}{l}\text { Bocken et al. (2019); } \\
\text { Pieroni et al. (2019a) }\end{array}$ \\
\hline R9 & $\begin{array}{l}\text { CE or broader sustainability objectives should be } \\
\text { firmly integrated into the tool and safeguarded when } \\
\text { the tool application is facilitated by others }\end{array}$ & Must-be & (ii) & $\begin{array}{l}\text { Bocken et al. (2019); } \\
\text { Pieroni et al. (2019a) }\end{array}$ \\
\hline R10 & $\begin{array}{l}\text { The tool should enable and guide the combination of } \\
\text { different types of BMs for CE during idea generation }\end{array}$ & Must-be & (iii) & Pieroni et al. (2019a) \\
\hline R11 & $\begin{array}{l}\text { The tool should envision all elements of the BM, } \\
\text { both from upstream and downstream architecture }\end{array}$ & Must-be & (iii) & Pieroni et al. (2019a) \\
\hline R12 & $\begin{array}{l}\text { The tool should support decision-making with } \\
\text { quantification of economic and environmental } \\
\text { potential }\end{array}$ & Must-be & (iii) & $\begin{array}{l}\text { Pieroni et al. (2019a); } \\
\text { Lieder and Rashid } \\
(2016)\end{array}$ \\
\hline R13 & $\begin{array}{l}\text { The tool should enable a holistic approach, i.e., from } \\
\text { design to implementation }\end{array}$ & Must-be & (iii) & Pieroni et al. (2019a) \\
\hline R13.1 & $\begin{array}{l}\text { The tool should enable and guide the identification } \\
\text { of different opportunities of CEBMs }\end{array}$ & Must-be & (iii) & Pieroni et al. (2019a) \\
\hline R13.2 & $\begin{array}{l}\text { The tool should enable and guide the detailing of the } \\
\text { CEBM concept and verification of its viability }\end{array}$ & Must-be & (iii) & Pieroni et al. (2019a) \\
\hline R13.3 & $\begin{array}{l}\text { The tool should support the implementation of } \\
\text { CEBMs }\end{array}$ & Must-be & (iii) & $\begin{array}{l}\text { Pieroni et al. (2019a); } \\
\text { Bocken et al. (2019) }\end{array}$ \\
\hline
\end{tabular}


The action research and the use of the low-fidelity prototype (documented in Pieroni et al., 2019c) enabled the identification of 9 additional requirements (R14-R22) and 2 specific requirements (R 14.1 and R16.1) (Table 2). In addition to the indication of relevance and categories, Table 2 also displays which companies endorsed the creation of each requirement.

Table 2. Practical requirements (R) (Legend - A/D: Small and medium (SME) electronics manufacturers; B: large heavy machinery manufacturer; C/E: SME furniture manufacturers; F: small textile manufacturer; G: large medical devices manufacturer)

\begin{tabular}{|l|l|l|l|l|}
\hline Code & Requirement description & Relevance & Category & Companies \\
\hline R14 & $\begin{array}{l}\text { The tool should provide suggestions to inspire new } \\
\text { business model concepts, i.e. preferably based on cases }\end{array}$ & Attractive & (iii) & A, B, C, E, G \\
\hline R14.1 & The tool should show detailed case examples & Attractive & (iii) & E, G \\
\hline R15 & The tool should focus on specific sectors & Must-be & (iii) & A, B, C, D, E, F, G \\
\hline R16 & $\begin{array}{l}\text { The tool should support the combination and prioritization } \\
\text { of opportunities and CEBM [overlap with R10] }\end{array}$ & Must-be & (iii) & B, C, D, F \\
\hline R16.1 & $\begin{array}{l}\text { The tool should focus on the business value (i.e., market } \\
\text { and economic potential) of CEBMs [synergy with R12] }\end{array}$ & Must-be & (iii) & B, E \\
\hline R17 & The tool should support a logic flow of decisions & Must-be & (iii) & C, D, F \\
\hline R18 & The tool should support communication and teamwork & Must-be & (iii) & B, G \\
\hline R19 & The tool should consider the ecosystem and collaborations & Attractive & (ii)/ (iii) & C \\
\hline R20 & $\begin{array}{l}\text { The value proposition definition should follow an iterative } \\
\text { process with explicit guidelines }\end{array}$ & Attractive & (iii) & A \\
\hline R21 & The tool should enable comparison of CEBM concepts & Attractive & (ii) & B, C \\
\hline R22 & $\begin{array}{l}\text { The tool should be a digital tool and designed for a } \\
\text { repeating process (i.e. enabling data storage and } \\
\text { migration) }\end{array}$ & Attractive & (ii) & C, E \\
\hline
\end{tabular}

Some practical requirements were consistent with or confirmed the conceptual requirements. For instance, R16 reinforces the requirement R10. Additionally, R16.1 has synergies with R12. However, in one case the practical requirement R15 conflicted with the conceptual requirement R6. This means that in literature the generation of tools for CEBM innovation has been promoted for generic applicability. However, in practice there seems to exist a preference for the contextualization of tools to the specific sector of application or at least the type of product (e.g. consumables vs. durable goods). This is associated to the easiness of assimilating terminologies, but also because different sectors present different systemic inefficiencies or sources of structural waste. Hence, different solutions are applicable. In summary, the requirements, which were originated from gaps described in literature and experienced in practice, point out for the need of a different tool from the ones available so far. Beyond other features, this tool should be: (i) prescriptive; (ii) accessible for self-facilitation; (iii) able to inspire change towards CE-thinking; (iv) holistic (i.e. all elements of BM and stages of BMI); (v) flexible to enable the combination of several types of CEBMs; (vi) sensitive to context (i.e. sector and product type), and; (iv) able to support decision-making with quantification of benefits for $\mathrm{CE}$ and sustainability.

\section{Developing a tool for Circular Economy Business Model Innovation}

This section explains how the conceptual and practical requirements were converted into functions for the development of the tool (section 4.1) and describes the prototype of the tool CEBM Configurator (section 4.2). In respect to the research questions (section 2), it provides answers for RQ2.

\subsection{Translation of requirements from literature and practice into a tool}

The final set of requirements (R) (section 3) enabled the definition of the main functions for the support tool. To translate the requirements in functions, we first organized the requirements by their impact in functions or scope. For instance, the requirement R13 was considered first because of its high impact in the overall structure and functions of the tool. R13 implied in developing a holistic tool that covers different stages of the BM innovation for CE. Therefore, a structure of modules was planned for the tool in order to cover functions in the different stages and their overall objectives 
specified by the specific requirements R13.1 (Table 3 and Table 4), R13.2 (Table 5), and R13.3 (Table 6). The remaining requirements were allocated after $\mathrm{R} 13$. Requirements $\mathrm{R} 1, \mathrm{R} 2, \mathrm{R} 3$ and $\mathrm{R} 4$ are related to the way that the tool is developed and will be incorporated in the next research stages of prototyping and evaluation. The requirements R5, R6, R7 (R7.1 \& R7.2), and R19 are related to the scope of application of the tool, and will be incorporated and refined during the tests of the highfidelity prototype with companies. Lastly, the requirement R22 demands a lot of time and resources, and might be considered in later stages depending on the outcomes of the evaluation of the highfidelity prototype (see discussion in section 5).

Table 3. Functions for Module 1- Sensing and identifying opportunities for CEBMs (R13.1)

\begin{tabular}{|l|l|l|l|l|}
\hline Step & $\mathbf{R}$ & Key function & Input & Output \\
\hline 1 & 9 & $\begin{array}{l}\text { Guidance on the } \\
\text { characterization of CE } \\
\text { challenges and identification of } \\
\text { opportunities for new CEBMs } \\
\text { (i.e. screening and sensing) }\end{array}$ & $\begin{array}{l}\text { Answers to 20 questions of } \\
\text { - productured questionnaire: } \\
\text { application } \\
- \text { weakness of current BM } \\
- \text { trends \& drivers for CE } \\
\text { - strategic CE intentions - } \\
\text { enablers in the ecosystem }\end{array}$ & $\begin{array}{l}\text { Information about CE problems } \\
\text { and opportunities }\end{array}$ \\
\hline $1 / 2$ & $\begin{array}{l}8,9 \\
10,14 \\
16,17\end{array}$ & $\begin{array}{l}\text { Recommendation of suitable } \\
\text { CEBM solution patterns (i.e. } \\
\text { best-practice configurations for } \\
\text { business models to solve a } \\
\text { specific identified and } \\
\text { repeatable challenge of CE) }\end{array}$ & $\begin{array}{l}\text { Information about CE } \\
\text { problems and opportunities }\end{array}$ & $\begin{array}{l}\text { List of BM solution patterns (i.e. } \\
\text { name, description, cases, } \\
\text { resource decoupling \& } \\
\text { economic benefits) } \\
\text { Graph to compare patterns based } \\
\text { on the adherence to the } \\
\text { screening questionnaire and the } \\
\text { degree of change in BMs }\end{array}$ \\
\hline
\end{tabular}

Table 4. Functions for Module 2- Designing CEBM concepts (R13.1)

\begin{tabular}{|l|l|l|l|l|}
\hline Step & $\mathbf{R}$ & Key function & Input & Output \\
\hline $2 / 3$ & 8,9 & $\begin{array}{l}\text { Recommendation of potential } \\
\text { combinations of CEBM } \\
\text { solution patterns (i.e., to design } \\
\text { a complete BM) }\end{array}$ & $\begin{array}{l}\text { Selection of individual } \\
\text { CEBM solution patterns } \\
\text { (from step 2) }\end{array}$ & $\begin{array}{l}\text { Recommendation of CEBM } \\
\text { concepts, i.e., likely } \\
\text { combination of solution patterns } \\
\text { for upstream and downstream } \\
\text { architecture (BM framework) }\end{array}$ \\
\hline 3 & $\begin{array}{l}16,13.1 \\
11,17 \\
18,20 \\
21\end{array}$ & $\begin{array}{l}\text { 3.1 Enabling the selection of } \\
\text { different configurations (i.e. } \\
\text { combinations) } \\
\text { 3.2 Enabling documentation of } \\
\text { ideation for BMs (i.e. defining } \\
\text { key actors, value proposition, } \\
\text { key benefits for actors \& CE) }\end{array}$ & $\begin{array}{l}\text { Selection of several CEBM } \\
\text { solution patterns to create } \\
\text { up to three whole CEBM } \\
\text { concepts }\end{array}$ & Business model concepts for CE \\
\hline
\end{tabular}

Table 5. Functions for Module 3 - Detailing or configuring CEBM concepts (R13.2)

\begin{tabular}{|c|c|c|c|c|}
\hline Step & $\mathbf{R}$ & Key function & Input & Output \\
\hline $3 / 4$ & $\begin{array}{l}9,14 \\
15 \\
21\end{array}$ & $\begin{array}{l}\text { Recommendation of potential } \\
\text { design options (DO) for } \\
\text { detailing each CEBM element }\end{array}$ & $\begin{array}{l}\text { Business model concepts } \\
\text { for } \mathrm{CE}\end{array}$ & $\begin{array}{l}\text { Recommendation of design } \\
\text { options for each element of the } \\
\text { CEBM }\end{array}$ \\
\hline 4 & $\begin{array}{l}13.2 \\
17,18 \\
21\end{array}$ & $\begin{array}{l}\text { Enabling documentation of } \\
\text { ideation process for checking } \\
\text { viability and detailing the } \\
\text { CEBM concept }\end{array}$ & $\begin{array}{l}\text { Selection of recommended } \\
\text { DO or creation of new DO } \\
\text { for CEBM elements }\end{array}$ & $\begin{array}{l}\text { Detailed CEBM concepts } \\
\text { Recommendation of resource } \\
\text { decoupling \& economic } \\
\text { indicators to evaluate CEBM } \\
\text { concepts }\end{array}$ \\
\hline
\end{tabular}


Table 6. Functions for Module 4 - Evaluating the potential of CEBM concepts (R13.3)

\begin{tabular}{|l|l|l|l|l|}
\hline Step & $\mathbf{R}$ & Key function & Input & Output \\
\hline 5 & 9,12 & $\begin{array}{l}\text { Support to the calculation of } \\
\text { the business case based on } \\
\text { input data }\end{array}$ & $\begin{array}{l}\text { Economic data (e.g. sales } \\
\text { forecast, price of offerings, } \\
\text { costs) }\end{array}$ & $\begin{array}{l}\text { Calculated indicators \& graph } \\
\text { (i.e. cash flow) for the economic } \\
\text { evaluation of CEBM concepts }\end{array}$ \\
\hline 6 & 9,12 & $\begin{array}{l}\text { Support to the calculation of } \\
\text { the environmental case based } \\
\text { on input data }\end{array}$ & $\begin{array}{l}\text { Resource efficiency data } \\
\text { (e.g. product lifetime, } \\
\text { failure times) }\end{array}$ & $\begin{array}{l}\text { Calculated indicators \& graph } \\
\text { (i.e. utility) for resource } \\
\text { decoupling potential of CEBM } \\
\text { concepts }\end{array}$ \\
\hline 7 & $\begin{array}{l}9,12 \\
13.3 \\
17,18\end{array}$ & $\begin{array}{l}\text { 1. Support to the consolidation } \\
\text { of indicators in a comparative } \\
\text { framework for CEBM concepts } \\
\text { 2. Enabling documentation of } \\
\text { trade-offs and action plans }\end{array}$ & $\begin{array}{l}\text { 1. Calculated indicators } \\
\text { (steps 6/7) } \\
\text { 2. Targets \& threshold } \\
\text { values }\end{array}$ & $\begin{array}{l}\text { Comparative analysis/evaluation } \\
\text { of CEBM concepts }\end{array}$ \\
\hline
\end{tabular}

\subsection{The prototype Circular Economy Business Model (CEBM) Configurator}

Based on the main functions (Table 3, Table 4, Table 5, and Table 6) the architecture of the support tool was defined (Figure 2) and used for the creation of a high-level prototype (sections 4.2.1 and 4.2.2).

\subsubsection{Format and content}

For the high-fidelity prototype version, the CEBM Configurator was structured in a spreadsheet software containing four modules and seven steps. Each step (section 3.2) correlates with one different spreadsheet of the tool that is visible for the users (i.e. primary level in Figure 2), plus spreadsheets for calculations (i.e. control level in Figure 2) or databases (i.e. support level in Figure 2).

Module 1 enables the identification of opportunities for designing new CEBMs. As output, the users receive suggestions of CEBM patterns that are suitable for their context and their CE challenges. BM patterns are best-practice configurations for business models to solve a specific identified and repeatable challenge (Amshoff et al., 2015). The logic of this module relies on a collection of sectorial CEBM patterns for upstream and downstream architecture and matrices for relating CEBM patterns, affected BM elements, and the questions from the questionnaire in Step 1 (Table 3). The CEBM patterns were identified based on analysis of more than 150 cases of companies that implemented CEBMs in six industry sectors (documented in Pieroni et al., 2019b).

Module 2 supports the transformation of opportunities into CEBM ideas. This means combining different CEBM patterns and adapting them to the company's context. As output, the users receive suggestions of potential synergies among different CEBM patterns to create complete BMs for CE. The recommendation of combination of CEBM patterns relies on matrices of usage and of potential combinations of CEBM patterns observed in the database of sectorial case studies. The likeability of one pattern being related with another specific pattern was calculated based on their recurrence in the sample of cases. After the free ideation exercise in Module 1, Module 2 enables the verification, improvement, or creation of other possible combinations.

Module 3 focuses on the configuration of detailed CEBM concepts. As output, the users receive suggestions of CE design/configuration options for all elements of the BM. This module is supported by a matrix relating the common practice or appropriate design options according to the selected combination of CEBM patterns. Design/configuration options are suggested for each BM element, including: overall benefits (i.e. economic, environmental and social); offerings (i.e. products and services); target customers; benefits for customers; partnerships and collaborations; benefits for partners; value delivery processes; value creation processes; and revenue mechanisms.

Module 4 envisions preliminary assessments of the customer value, economic, and resource decoupling potential for the designed CEBMs. As output, the users receive the calculations of composite indicators (e.g. return on investment, net present value, payback, cash flow, longevity, utility) and a comparative framework of scenarios to guide decision-making. The assessment of the economic potential is based on cost-benefit analysis and is structured as a 'business case', applying both quantitative and qualitative measures. The assessment of the resource decoupling potential is 
based on qualitative and quantitative measures (e.g. longevity, utility, energy consumption) (Kjaer et al., 2019; Kravchenko et al., 2019).

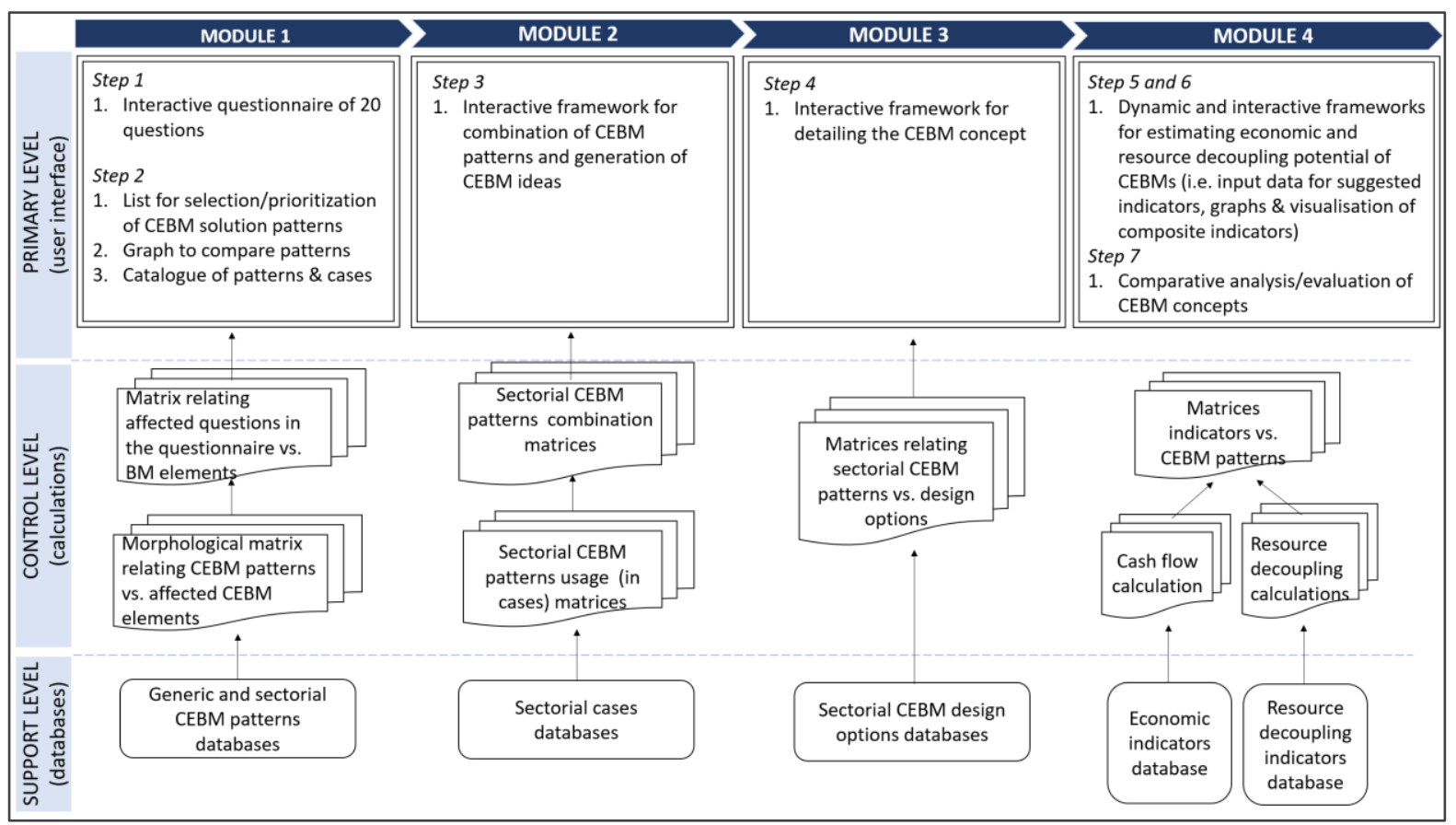

Figure 2. Architecture of the tool Circular Economy Business Model Configurator

\subsubsection{Purpose and scope of application}

The CEBM Configurator is expected to support facilitators or process champions within manufacturing companies to trigger a change of mindset towards $\mathrm{CE}$ within their organizations. $\mathrm{CE}$ will require 'breaking industry recipes' (Matthyssens et al., 2006) and the silo/organizational-centric view. However, some actor in the value chain has to take the lead in thinking about $\mathrm{CE}$ and breaking the resistance (Perey et al., 2018). This process starts internally in one organization until they absorb the concepts and are confident and able to influence other external actors (i.e. suppliers, customers, municipalities) and create collaborative initiatives. The CEBM Configurator seeks to incentivize more of those individual actors acting in the position of manufacturers to change their way of operating, consequently influencing others.

Our hypothesis is that based on an existing scope (i.e. selected product that needs to fit with CEcontext, initial BM idea for CE), the CEBM Configurator can support specific sub-sectors of manufacturing companies and their business developers, sustainability managers, or product managers to strengthen proposals of business model concepts for $\mathrm{CE}$ before seeking for funding and implementation sponsors. The users of the CEBM Configurator will benefit by:

- obtaining inspiration of best practices;

- confirming assumptions with a structured framework;

- receiving a logic structure and being prompted for decision-making and prioritization;

- keeping an accounting of decisions.

Moreover, the CEBM Configurator can work as a facilitating tool for trained process champions or facilitators that will engage a multifunctional team (e.g. sales, marketing, finances, procurement, manufacturing, operations and logistics, engineering and product design, business innovation, digital technologies, services operations or after-sales, corporate social responsibility). It will function as a 'side consultant' to the facilitators, generating information that can be used to populate interactive frameworks (e.g. cards, business model framework) that are suitable for group discussions and flexible to 'live changes'. 


\section{Next steps and concluding remarks}

This research aimed to generate adequate knowledge to and with businesses in order to enable them to identify and demonstrate viability, economic feasibility, and resource decoupling potential of business models for CE. Based on a design research methodology, 22 conceptual and practical requirements were identified and translated in functions that enabled the conceptualisation of a new tool called CEBM Configurator. This tool guides manufacturing companies throughout four modules and seven steps, enabling them to identify opportunities for CE, detail business model concepts, and evaluate their economic and resource decoupling potential.

The research conducted so far presents some limitations. First, the nature of the literature review techniques for the identification of conceptual requirements included snowballing and grey literature, which might have generated selection bias. A second limitation is related to the reduced sample size of companies participating in the action research, which cannot guarantee generalization of the practical requirements to all sub-sectors that the tool was developed for. To deal with those limitations and to test our hypothesis, we conducted preliminary case studies with manufacturing companies from four different sectors. These companies worked independently with the CEBM Configurator high-fidelity prototype in the real scenarios of their organizations after they received introductory training. Preliminary results point to a positive uptake by companies, which valued the ability of the tool in providing a structured framework to guide and support decision-making with knowledge during the configuration of CEBMs. Moreover, the diversity of the sample points out to the applicability of the tool in different companies' sizes and sectors, especially furniture and electrical equipment/appliances. However, additional tests and evaluations are required, such as:

1. Case studies with manufacturing companies from different sectors and sizes working independently in the real scenarios of their companies after they receive introductory training. This will be a way to falsify/confirm the hypothesis that the tool can support different companies' sizes and the sectors that it was developed for.

2. Case studies within manufacturing companies from different sectors with the participation of researchers facilitating and observing the use of the tool by companies. This will be a way to falsify/confirm the hypothesis that trained facilitators can use the CEBM Configurator independently with quality (when compared to external facilitators or consultants).

After the thorough evaluation of the tool for confirmation of its scope and applicability, the requirement R22 (i.e. a digital web-based tool) could be contemplated to enhance the usability of the tool.

The research contributes to literature by systematizing and consolidating requirements from theory and practice for tool development for CEBM innovation. Additionally, it can help manufacturing companies that are preparing to engage in $\mathrm{CE}$ and need to plan for or strengthen new BM proposals.

\section{Acknowledgement}

This article is one of the outcomes of the research project CIRCit (Circular Economy Integration in the Nordic Industry for Enhanced Sustainability and Competitiveness), which is part of the Nordic Green Growth Research and Innovation Programme (grant numbers: 83144) and jointly funded by NordForsk, Nordic Energy Research, and Nordic Innovation. The authors would like to thank the CIRCit consortium for facilitating the engagement with companies. Special thanks go to the participating companies for the opportunity and collaboration.

\section{References}

Amshoff, B. et al. (2015), "Business Model Patterns for Disruptive Technologies", International Journal of Innovation Management, Vol. 19 No. 03, p. 1540002.

Andreasen, M.M. (2011), “45 Years with design methodology”, Journal of Engineering Design, Vol. 22 No. 5 , pp. 293-332.

Boehm, B.W. (1984), "Verifying and Validating Software Requirements and Design Specifications", IEEE Software, Vol. 1 No. 1, pp. 75-88.

Blessing, L.T.M. and Chakrabarti, A. (2009), DRM, a Design Research Methodology, Springer, London, https://doi.org/10.1007/978-1-84882-587-1

Blomsma, F. and Brennan, G. (2017), "The Emergence of Circular Economy: A New Framing Around Prolonging Resource Productivity”, Journal of Industrial Ecology, Vol. 21 No. 3, pp. 603-614. 
Bocken, N. et al. (2019), "A Review and Evaluation of Circular Business Model Innovation Tools", Sustainability, Vol. 11 No. 8, p. 2210.

Bocken, N.M.P. et al. (2016), "Product design and business model strategies for a circular economy", Journal of Industrial and Production Engineering, Vol. 33 No. 5, pp. 308-320.

Böhringer, C. and Rutherford, T.F. (2015), "The Circular Economy - An Economic Impact Assessment", Report to SUN-IZA, No. June, pp. 1-33.

Chakrabarti, A., Morgenstern, S. and Knaab, H. (2004), "Identification and application of requirements and their impact on the design process: A protocol study", Research in Engineering Design, Vol. 15 No. 1, pp. 22-39.

Garetti, M., Rosa, P. and Terzi, S. (2012), "Life Cycle Simulation for the design of Product-Service Systems", Computers in Industry, Elsevier B.V., Vol. 63 No. 4, pp. 361-369.

Geissdoerfer, M. et al. (2017), “The Circular Economy - A new sustainability paradigm?”, Journal of Cleaner Production, Vol. 143 No. January, pp. 757-768.

Kirchherr, J. and van Santen, R. (2019), "Research on the circular economy: A critique of the field", Resources, Conservation and Recycling, Vol. 151 No. September, p. 104480.

Kjaer, L.L. et al. (2019), "Product/Service-Systems for a Circular Economy: The Route to Decoupling Economic Growth from Resource Consumption?”, Journal of Industrial Ecology, Vol. 23 No. 1, pp. 22-35.

Kravchenko, M., Pigosso, D.C. and McAloone, T.C. (2019), "Towards the ex-ante sustainability screening of circular economy initiatives in manufacturing companies: Consolidation of leading sustainability-related performance indicators", Journal of Cleaner Production, Elsevier Ltd, Vol. 241, p. 118318.

Lieder, M. and Rashid, A. (2016), "Towards circular economy implementation: a comprehensive review in context of manufacturing industry”, Journal of Cleaner Production, Vol. 115, pp. 36-51.

Matthyssens, P., Vandenbempt, K. and Berghman, L. (2006), "Value innovation in business markets : Breaking the industry recipe", Vol. 35, pp. 751-761.

Matzler, K. and Hinterhuber, H.H. (1998), "How to make product development projects more successful by integrating Kano's model of customer satisfaction into quality function deployment", Technovation, Vol. 18 No. 1, pp. 25-38.

McAloone, T.C. (2019), "Transitioning to the Circular Economy: What does it take to go from efficiency to effectivness?", Effektivitet, Available at: http://circitnord.com/wp-content/uploads/2019/04/Transitioning-tothe-Circular-Economy-What-does-it-take-to-go-from-efficiency-to-effectivness_Tim-C_-McAloone_ Professor_-DTU-.pdf.

OECD. (2018), "Business Models for the Circular Economy Re-Circle", https://www.oecd.org/environment /waste/policy-highlights-business-models-for-the-circular-economy.pdf (accessed January 2020).

Pieroni, M.P.P., McAloone, C.T. and Pigosso, C.A.D. (2019c), "Configuring New Business Models for Circular Economy through Product-Service Systems", Sustainability, Vol. 11 No. 13, p. 3727.

Pacheco, C. and Garcia, I. (2012), "A systematic literature review of stakeholder identification methods in requirements elicitation”, Journal of Systems and Software, Elsevier Inc., Vol. 85 No. 9, pp. 2171-2181.

Perey, R. et al. (2018), "The place of waste: Changing business value for the circular economy", Business Strategy and the Environment, Vol. 27 No. 5, pp. 631-642.

Pieroni, M.P.P., McAloone, T.C. and Pigosso, D.C.A. (2019a), "Business model innovation for circular economy and sustainability: A review of approaches", Journal of Cleaner Production, Vol. 215, pp. 198216.

Pieroni, M.P.P., McAloone, T.C. and Pigosso, D.C.A. (2019b), "Configuring new business models for circular economy: from patterns and design options to action", 4th International Conference on New Business Models, Manuscript In Press.

Rosa, P., Sassanelli, C. and Terzi, S. (2019), "Towards Circular Business Models: A systematic literature review on classification frameworks and archetypes", Journal of Cleaner Production, Elsevier Ltd., Vol. 236, p. 117696.

Schroeder, P., Anggraeni, K. and Weber, U. (2019), "The Relevance of Circular Economy Practices to the Sustainable Development Goals", Journal of Industrial Ecology, Vol. 23 No. 1, pp. 77-95.

Schulte, U.G. (2013), "New business models for a radical change in resource efficiency", Environmental Innovation and Societal Transitions, Elsevier B.V., Vol. 9, pp. 43-47.

Teece, D.J. (2010), "Business Models, Business Strategy and Innovation”, Long Range Planning, Elsevier Ltd., Vol. 43 No. 2-3, pp. 172-194.

Yin, R.K. (2011), Qualitative Research from Start to Finish, Vol. 53, The Guilford Press, New York. 